\title{
A morte na visão do sertanejo nordestino em tratamento oncológico
}

\author{
Lana Veras \\ Universidade Estadual do Rio de Janeiro \\ Virginia Moreira \\ Universidade de Fortaleza
}

\begin{abstract}
Resumo
O estudo objetivou compreender como o sertanejo com câncer lida com a morte. Três temáticas foram entrelaçadas nesta pesquisa: a morte em seus aspectos históricos e psicológicos; a realidade histórico-cultural do homem do sertão nordestino brasileiro; e a pessoa com câncer em sociedade. Utilizou-se uma abordagem qualitativa e método fenomenológico, os instrumentos de coleta de dados foram: a observação participante e a entrevista fenomenológica. Concluiu-se que a população pesquisada percebe a morte com mais familiaridade, que as formas de enfrentamento perpassam pela fé, que a vivência do adoecimento é modulada por aspectos psicossociais e culturais e que os rituais funerários tradicionais estão sendo modificados diante de uma lógica de mercantilização da morte.
\end{abstract}

Palavras-chave: morte; psico-oncologia; psicologia social; fenomenologia.

\begin{abstract}
Death in the vision of northeast backcountry of Brasil in cancer treatment. This study aimed to understand how the backcountry with cancer sees death. Three themes were interwoven in this research: death in its historical and psychological aspects; the historical and cultural realities of man`s Northeast Backcountry of Brazil, and the person with cancer in society. A qualitive approach and the critical phenomenological method were used, having as instruments of data collection the participant observation and phenomenological interview. It was concluded that the backcountry perceives death with more familiarity, that permeate the ways of coping through faith, that the experience of illness is modulated by psychosocial and cultural aspects and traditional funeral rituals are being modified facing logic of merchantilizing of the death.
\end{abstract}

Keywords: death; psycho-oncology; social psychology; phenomenology.

\section{Introdução}

Apesar dos grandes avanços no tratamento e do aumento nos índices de cura, o câncer ainda é uma patologia muito associada à morte. Mesmo com a valorização dos aspectos subjetivos do paciente oncológico e de sua relação com a morte e o morrer, ocorrida nos últimos anos, Valle (2006) observou que: "a percepção que o paciente elabora das vivências de morte e do morrer ainda tem sido pouco investigada" (p.363). A consciência da finitude é uma característica comum a todos os seres humanos, mas a maneira que cada comunidade desenvolve para se relacionar com a morte é peculiar, influenciada por questões histórico-sociais e culturais (Aries, 2003; Kovács, 2002, 2007; Menezes, 2004).

O contato com a realidade de sertanejos nordestinos com câncer evidenciou especificidades na forma dessas pessoas perceberem a perda. Esta pesquisa pretendeu compreender essa realidade, entendendo que o ser humano se constitui em uma relação de mutualidade com o mundo (Merleau-Ponty, 2006; Moreira, 2004). Para discutir a questão, este estudo explanou sobre a realidade histórico-cultural do homem do sertão nordestino em seus aspectos ligados à perda; versou sobre a morte em suas facetas históricas e psicológicas e sobre a pessoa com câncer em sociedade. Por meio dos depoimentos dos pacientes e do referencial teórico, teceu-se um entrelaçamento das temáticas: morte, sertanejo e câncer.

A partir de entrevistas com pacientes em tratamento oncológico, oriundos de cidades do sertão nordestino brasileiro, e observações participantes, buscou-se compreender a "Morte Severina", já descrita nos versos do poeta João Cabral de Melo Neto (2000): "E se somos Severinos iguais em tudo na vida, morremos de morte igual mesma morte Severina: que é a morte de que se morre de velhice antes dos trinta, de emboscada antes dos vinte, de fome um pouco por dia" (p.46).

A maioria das pesquisas sobre como as pessoas e grupos dão sentido à morte, como a simbolizam e a enfrentam consideram como parâmetros construções teóricas desenvolvidas em países da Europa e da América do Norte. Como exemplo: os estágios de Kubler-Ross (2005), as fases de Bolwby (1973) e as tarefas de Worden (1998). Apesar da relevância desses estudos, o trabalho com a realidade do sertanejo com câncer demandou uma nova compreensão das singularidades dessas pessoas em seu grupo sociocultural, visto que o material teórico citado, frequentemente, não observava as peculiaridades culturais, enfocando estudos 
feitos com população urbana de países desenvolvidos, que apresentam bom nível de escolaridade e condição econômica satisfatória. Observou-se a carência de estudos que abordam a psico-oncologia por meio de um olhar fenomenológico e que enfocasse as peculiaridades da população do Nordeste brasileiro.

A realidade da pobreza, fome crônica, violência, pouco acesso à saúde e exposição mais frequente à morte não teria influência na forma como esse grupo de pessoas percebe os processos de perda? E os psicólogos, que se propõem a acompanhá-los durante o adoecimento e o tratamento estão preparados para compreender essas particularidades? Como o profissional de psicologia poderia intervir em um contexto tão diverso do teorizado? Como ajudar o outro se colocando como um "diferente melhor" ou como um "igual generalizador", esfumaçando diferenças socioculturais?

O objetivo deste estudo foi compreender os sentidos atribuídos à morte pelo sertanejo em tratamento oncológico. A compreensão teórica dos temas: morte, sertanejo e câncer será apresentada, seguida de discussão sobre a pesquisa fenomenológica crítica realizada por meio de entrevistas fenomenológicas e observação participante.

A Morte: aspectos históricos e psicológicos. Phillipe Ariès (2003) encerrou a primeira parte, chamada Atitudes diante da morte, de seu clássico estudo "História da morte no ocidente" com o seguinte questionamento: "Existirá uma relação permanente entre a ideia que se tem da morte e a que fazemos de nós mesmos?" (p.103). A partir do estudo feito pelo citado historiador francês, nota-se que a forma como o homem dá sentido à morte e trabalha suas perdas está ligada à maneira como ele se percebe, e o que o seu mundo, sua época e suas vivências o permitem. Quem somos nós? Como vivemos? Essas seriam as perguntas iniciais para se responder outra: quais sentidos atribuímos à morte?

Ariès (2003) descreveu algumas atitudes diante da morte assumidas pelo homem ocidental ao longo do tempo. Iniciando pela categoria que denominou "morte domada", quando a morte era vista como familiar e próxima e seus rituais eram públicos até o período que denomina "Morte Interdita", momento em que existe uma modificação na maneira de tratar a morte, passando-a de familiar para vergonhosa e interdita. Dessa forma, a morte é medicalizada e seu local é transferido do leito do quarto para o leito do hospital, passando de ritual público para privado e restrito, alterando seu caráter familiar. O temor da morte é, ao mesmo tempo, aumentado e negado, de modo que, cada vez mais, morra-se como tememos: sozinhos.

Sobre essa atitude ocidental contemporânea diante da morte, Kovács (2002) observou que, de evento natural ao desenvolvimento humano, a morte passa a ser concebida como fracasso, impotência ou imperícia, devendo ser ocultada e silenciada.

Edgar Morin (1970), em "O Homem e a Morte" sugeriu uma reflexão sobre a relação morte-indivíduo-espécie, observando que a morte pode ser vista como uma derrota no aspecto particular, mas como uma vitória considerando toda a espécie. $\mathrm{O}$ autor analisou a morte, enquanto necessidade, dentro de um quadro de referência maior do que o individual, pois somente a partir de sucessivos fins e nascimentos é que as espécies evoluem, se adaptam e sobrevivem nos seus ambientes, diante do fato que só com a morte individual é que a vida geral pode continuar. Morin (1970) lembrou que o fortalecimento do conceito de indivíduo, a consciência da morte e seu traumatismo atingem seu pico, gerando necessidade de negação com crenças de imortalidade. Desta forma, vê-se o medo da morte com mais intensidade nas sociedades modernas e contemporâneas. $\mathrm{O}$ ocidente, nos séculos XX e XXI, assiste à patologização do luto, sua manifestação pública ou sua insistente expressão privada passa a ser relacionada à fraqueza, e é motivo de preocupação, merecendo intervenções medicalizantes e tornando o luto mais individual do que social e ritualizado (Ariès, 1990).

A Morte e a vida Severina. A visão de homem corrente, nesta pesquisa, vai ao encontro da do educador Paulo Freire (2005), que propôs: “a negação do homem abstrato, isolado, solto, desligado do mundo, assim como também a negação do mundo como uma realidade ausente dos homens" (p.81). A fala de Freire remete ao homem mundano de Merleau-Ponty (2006) e ao seu conceito de atolamento congênito no mundo, realçando a relevância do contexto social na constituição da subjetividade do homem, pois a forma como ele se vê no mundo, como se expressa nele, seus sentimentos e suas relações com os outros, enfim, a maneira como existe, é forjada neste processo de mútua constituição (Moreira, 2004).

A realidade sócio-histórica não somente influencia como variável, ela é a base da emergência do ser enquanto sujeito. Ewald e Soares (2007) afirmaram que, na formação do si-mesmo, há o compartilhar de nossa condição, incluindo valores, crenças, gênero e tempo. O reconhecimento deste processo torna imprescindível, para a compreensão da morte na visão do sertanejo com câncer, conhecer o que se chama sertão e quem é o sertanejo, neste estudo.

Compreender a trajetória histórica do sertanejo é fundamental na tentativa de compreensão do seu vivido. A maneira como vive está ligada tanto a sua experiência pessoal como também à trajetória do seu povo. Na história do homem do sertão nordestino aparecem situações, eventos e movimentos como a seca, o cangaço, o êxodo, a pobreza, a desigualdade social, a fome e a fé (Villa, 2000), fatores que o colocam frente à necessidade de significar a sua vida e a sua morte de uma forma peculiar, congruente a seu vivido.

Aresistência sertaneja foi enfatizada por Euclides da Cunha (2007) em Os Sertões: campanha de canudos: “Os sertanejos inverteriam toda a psicologia da guerra: enrijavam-nos os reveses, robustecia-os a fome, empedernia-os a derrota". E por meio de sua consagrada constatação: "o sertanejo é antes de tudo um forte" (p.629).

A ambivalência e a polaridade são presentes no sertão do Nordeste, onde se observa a alternância entre miséria e riqueza, seca e fartura, violência e solidariedade. A convivência com esses pares ultrapassa o dualismo, integrando em um mesmo homem suas múltiplas facetas e possibilidades. Existe uma congruência entre o pensamento de MerleauPonty (1975) e Guimarães Rosa (2007) quando o primeiro asseverou que o homem é estofo do mundo, o mundo é homem e o homem é mundo, ao mesmo tempo que Guimarães Rosa afirmou: "O sertão está em toda parte, o sertão está dentro da gente". Os dois autores explicitam a impossibilidade do ser humano ser compreendido dissociado de sua realidade histórica e social, não é possível um "homem-médio" que represente todos os outros.

A constante alternância ou convivência com essas polaridades, 
que trazem extremos tão diversos, mostra que a frequente exposição às mudanças é vivência característica do homem sertanejo. Assim, é importante perceber que essas mudanças vêm acopladas a respectivos processos de perdas e a seus decorrentes trabalhos de luto. O sertanejo é, então, um homem que se depara cotidianamente com o perder, de maneira que é constantemente colocado perante a finitude, desde seu processo de construção, como povo, até sua história pessoal como indivíduo.

Porém, não é exclusividade do homem nordestino o caráter transitório da vida, na verdade essa é uma característica que se apresenta como natural a todos os seres vivos. O que não é natural, mas construído sócio-historicamente, é a forma como cada povo ou indivíduo é exposto e como vivencia essa efemeridade na vida. A afirmativa de Freire (2005): "Não há vida sem morte, como não há morte sem vida, mas há também uma 'morte em vida'. E a 'morte em vida' é exatamente a vida proibida de ser vida" (p.197), faz refletir sobre as diferenças entre vivenciar a infalibilidade da morte como evento natural e a exposição a perdas determinadas por modelos econômicos e sociais, reproduzidos ao longo da história do sertanejo.

AMorte e o sertanejo com câncer. Em uma definição biomédica, um câncer é resultado da proliferação de uma linhagem de células que, com mutações em seus genes, perdem a capacidade de morte celular (apoptose) e se multiplicam rapidamente, invadindo tecidos vizinhos e migrando para outras partes do corpo, em um processo metastático (Camponero, 2008). Mas para compreender a pessoa com câncer é importante, além de questionar "Que doença é essa?", perguntar-se: "Quem é essa pessoa?" O conhecimento biomédico é importante na compreensão do adoecer, porém, o adoecimento é da ordem do experiencial, logo não é possível encará-lo como um processo universal. Langdon (2001) reiterou esse posicionamento afirmando que: "A doença é um processo experiencial; suas manifestações dependem dos fatores culturais, sociais e psicológicos que operam em conjunto com os processos psico-biológicos" (p.242).

Se o processo de adoecer é construído considerando aspectos socioculturais, o que falar dos tratamentos que são construções claramente humanas? Cada modelo de saúde propõe os tratamentos nos quais acredita; o Brasil é um país em que o sincretismo religioso e cultural propicia uma diversidade de possibilidades neste tópico. É possível que uma mesma pessoa ou grupo social utilize várias alternativas, como a tecnologia biomédica, o conhecimento fitoterápico popular, as orações ou outros rituais ligados à fé. (Gorzoni, 2005; Silva \& Salvajoli 2008; Straub, 2002)

Amaneira como as pessoas lidam com processos de adoecimento está estritamente relacionada ao seu conceito de saúde. Uma das áreas de estudo que têm contribuído para a constituição de uma maneira mais holística de perceber o homem, sua saúde e seu adoecimento é a antropologia médica (Kleinman \& Good, 1985). Os estudos nesta área ajudam a psico-oncologia a compreender cada processo de adoecimento e cada paciente como singular, e, desta forma, propor estratégias terapêuticas que contemplem essas peculiaridades, tornando-as, desta forma, mais efetivas.

As pessoas não adoecem da mesma forma em todas as regiões e comunidades do mundo. Além de cada região possuir seu quadro epidemiológico próprio, as mesmas doenças podem acometer as pessoas de maneiras diversas. Os trabalhos de pesquisa, desenvolvidos pelos professores Arthur Kleinman e Byron Good(1985), em Havard, já apresentavam a importância de perceber que as desordens só podem ser compreendidas por meio da mediação cultural. Estes pesquisadores questionaram o "naturalismo" biomédico, favorecendo uma maior tolerância frente às demais formas de entender e de agir diante da doença. De modo que uma única visão do adoecer será sempre incompleta.

Para compreender como uma pessoa lida com seu adoecimento é necessário, segundo Helman (2006), "entender um pouco da lente através da qual elas enxergam e interpretam o mundo" (p.15). Portanto, uma psico-oncologia, que se proponha mundana, no sentindo merleau-pontyano, deve emergir nesse contexto tentando fazer da interface entre esses dois saberes (psicologia e oncologia) um espaço de comunicação, de identificação de objetivos comuns e de tolerância com as diferenças.

\section{Procedimentos metodológicos}

A pesquisa foi delineada na abordagem qualitativa, que considera a realidade como socialmente construída (Denzin \& Lincoln 2007). Para alcançar a compreensão da morte na visão do sertanejo com câncer, foi utilizado o método fenomenológico crítico, com a utilização conjunta de instrumentos etnográficos e de entrevistas fenomenológicas, conforme Moreira e Cavalcante (2008). A pesquisa se efetuou em dois momentos diferentes: o primeiro, no hospital e casa de apoio, onde o paciente com câncer faz seu tratamento; e o segundo, na cidade de origem do paciente, no sertão nordestino.

No Hospital do Câncer do Ceará, foram realizadas entrevistas fenomenológicas com 7 (sete) pacientes referenciados de cidades do sertão nordestino e que realizavam tratamento oncológico. Posteriormente, dois dos pacientes foram visitados em seus domicílios de origem: cidades do sertão nordestino onde residem, IndependênciaCE e Quixeramobim-CE. Na ocasião das visitas às referidas cidades, foram utilizados instrumentos etnográficos como observações participantes e entrevistas informais com o sujeito colaborador e demais pessoas de seu convívio, ou envolvidas com a temática da pesquisa.

Para apreender os sentidos do vivido compartilhado, as entrevistas gravadas em áudio, na casa de apoio do hospital, foram transcritas na íntegra e analisadas segundo o método fenomenológico crítico $\mathrm{O}$ material obtido foi trabalhado em conformidade com alguns passos indicados e detalhados em Moreira (2004) e descritos sumariamente a seguir: 1) Transcrição da entrevista para obtenção do texto nativo: transcrição literal das falas dos colaboradores e entrevistador, incluindo detalhes como pausas, choro, silêncios ou mudanças no timbre de voz. 2) Divisão do texto nativo em movimentos: busca e aglutinação de tons semelhantes dentro da transcrição literal da entrevista. 3) Análise dos Sentidos Emergentes: procurou-se sistematizar uma articulação entre os sentidos emergentes, identificando e compreendendo os diversos significados atribuídos pelo sujeito. 4) "Saindo dos Parênteses" como ferramenta crítica: implicação do pesquisador no processo, posicionando-se perante os resultados da investigação, realizouse um diálogo entre os conteúdos teóricos e o conteúdo das falas dos sujeitos.

As vinhetas, originadas das observações feitas na casa de apoio do hospital e nas cidades sertanejas de origem de dois dos sete colaboradores, foram analisadas culturalmente. Essa análise teve seu 
conteúdo entrelaçado com os sentidos emergentes das entrevistas fenomenológicas, de modo a facilitar a compreensão do fenômeno dentro de seu caráter mundano.

No primeiro momento da pesquisa, a escolha dos entrevistados se deu a partir da parceria com o serviço de psicologia do referido hospital, que indicou possíveis sujeitos colaboradores. Realizaram-se duas entrevistas com cada colaborador, na casa de apoio do hospital. A primeira foi destinada à apresentação, construção de vínculo, acolhimento, discussão de pontos importantes para a concessão do consentimento livre e esclarecido dos participantes como: objetivos da pesquisa, relação risco/benefício, sigilo da identidade e não obrigatoriedade da participação. A segunda foi a entrevista fenomenológica propriamente dita, envolvendo mais enfaticamente o tema da pesquisa, a partir de uma pergunta disparadora: "O(a) Senhor(a) poderia nos falar o que é a morte para o(a) senhor(a)?"

No segundo momento da pesquisa, a escolha de quais pacientes seriam visitados em seus domicílios aconteceu considerando a disponibilidade dessas pessoas em serem visitadas e a presença das mesmas em suas cidades até o fim do período da realização de entrevistas e observações. Pois, durante o tratamento oncológico, elas permaneciam hospedadas na casa de apoio do hospital, localizada na capital do estado. Assim, as visitas realizadas a esses pacientes ocorreram nos intervalos de seus tratamentos, ocasião em que, às vezes, retornavam para suas casas.

Neste artigo, são citados alguns trechos de entrevistas realizadas durante a pesquisa. Foram atribuídos nomes fictícios aos pacientes, para a manutenção do sigilo de sua identidade, como acordado no termo de consentimento. Essa pesquisa seguiu os princípios éticos e as diretrizes presentes na resolução 196/96 do Conselho Nacional de Saúde- Ministério da Saúde e foi aprovada pelo Comitê de Ética em Pesquisa do Hospital do Câncer do Ceará por meio de parecer consubstanciado favorável à sua realização.

\section{Resultados e discussão}

\section{Entrevistas}

Durante a análise das entrevistas alguns temas foram emergentes; eles serão apresentados com a ajuda de trechos das falas dos colaboradores.

\section{Morte Severina}

Esse tema emerge como central nas falas dos entrevistados, contém compreensões da finitude e expressão de vivências com a morte do outro, a partir de experiências com perdas de familiares e amigos. As formas de enfrentamento aparecem, em sua maioria, ligadas à fé e à resignação. Os rituais funerários são expostos em suas expressões tradicionais e também em novos formatos e configurações. Para facilitar a compreensão, foram organizados subtemas emergentes que constituem o tema Morte Severina, com trechos de depoimentos de pacientes entrevistados neste estudo.

A morte é... Um dos entrevistados, um senhor de 79 anos, com muitas vivências relacionadas a perdas, relatou como percebe a morte. Um trecho de seu depoimento, citado abaixo, retrata essa percepção:

A gente sabe que a morte é um dever de cada um, ela vem pra qualquer um, é um pedaço do seu corpo que se tira sem anestésico. (...) Quando a gente recebe uma noticia dessas é uma pancada por trás que ninguém espera, a gente fica vivo mais sente a dor. Quando a gente tá esperando, aí tudo bem, mas se é surpresa aí é uma pancada por trás. (A. Severino, entrevista pessoal, 13 de março de 2009).

Sua fala não nega a morte, vendo-a como um “dever", ela é iniludível, mas não nega, também, o sofrimento, e usa uma imagem: "é um pedaço do corpo que se tira sem anestésico". Seu Severino fala na inevitabilidade da dor, e da reabilitação de quem por ela passa, quando afirma: “A gente fica vivo, mas sente a dor". Referiu-se, ainda, a outra questão de relevante discussão: a forma como se deu a morte: foi esperada? Foi repentina? Para ele, a morte, quando surpresa, é "uma pancada por trás"; se esperada, não. Seu ponto de vista é semelhante à forma como as pessoas lidavam com esse fato na descrição de Ariès (2003) da "Morte Domada", quando a morte súbita era indesejada, por ser desonrosa, não dando oportunidade para que a pessoa realizasse rituais importantes e tomasse as providências necessárias. Essa atitude diante da morte contrasta com a relação com a morte que possuem muitas pessoas da contemporaneidade, como descreveram Soares e Dantas (2006): "O homem hipermoderno tende a ver a morte como uma traição, cometida pela tecnociência, que se apresentou a ele como onisciente e onipotente, que lhe prometeu eterna juventude e imortalidade" (p.100).

Outra paciente entrevistada, uma senhora de 58 anos, expressou que: "pras pessoa morrer, assim de repente, até de uma preocupação morre" (Conceição, entrevista pessoal, 18 de março de 2009), e, assim, demonstrou uma compreensão mais holística da saúde, na qual as etiologias não têm caráter exclusivamente biomédico (Di Nola, 2007, Helman, 2006; Rodrigues, 2007). Afirmou, ainda, que "a morte quer uma desculpa", se remetendo à infalibilidade da morte. Seus relatos expõem uma visão do morrer como algo do qual não se pode fugir, e não há como mudar o que parece ter sido predeterminado.

A morte como conhecida. A frequência dos óbitos de filhos pequenos pode ser observada no trecho da entrevista de uma senhora de 59 anos, transcrito adiante.

Tive 13 filhos, morreram 4 e tem 9 . O primeiro morreu criancinha assim nos braço, morreu novinho, nem se sentava ainda. Agora a outra apareceu uns caroços assim na cabeça dela, ela só andava se segurando nas paredes, ta entendendo? não conseguia andar só não. Aí eu banhei ela, que banhei foi esse que depois desse banho aí a bichinha morreu desse banho, nos demo tanto remédio pra ela, mas esse tempo não tinha o médico(...) Eu já disse duas né? Agora o outro, ele já tava se arrastando pelo chão. Eu tava gorda de outro(...) A outra, Antônia, com 14 anos morreu afogada. Eu sube quando eu tava com um buchão de um caçula que eu tenho, aí chegou um irmão meu, ficou por ali de conversa por fora e aí disse 'Cumade eu vim aqui dizer que é pra ir pegar a Maria Antonia que ela morreu afogada' aî truxeram ela, quando ela morreu faltava 3 meses pra eu ganhar nenê). (M. Josefa, entrevista pessoal, 17 de abril de 2009). 
Nesse trecho da fala de Dona M. Josefa, é relevante observar que ela relata a morte dos filhos sem nomear os três primeiros, refere-se a eles como: "O primeiro", "a outra" $e$ "o outro". No meio da narrativa, a frase "eu já disse duas né?" é reflexo da realidade em que era preciso contar o número de filhos perdidos (Villa, 2000). Somente Antônia, sua filha que morreu aos quatorze anos, foi citada pelo nome, e neste momento do relato a paciente chora. Dona M. Josefa, grávida de seis meses, recebeu a notícia da morte da filha de forma clara e objetiva, já que o mecanismo de negação da perda é difícil de ser utilizado em uma comunidade que a vivencia no cotidiano (Villa, 2000).

Outro tema muito forte nas entrevistas refere-se à importância da presença no momento da morte do outro. $\mathrm{Na}$ contemporaneidade, principalmente em zonas urbanas, mantém-se uma relação medicalizada e institucionalizada com a morte, o lócus da morte não é mais a casa e com a presença da comunidade, acontece, agora, em instituições de saúde, como o hospital, e assistida por profissionais (Aries, 1990, 2003; Kovács, 2002, 2007). Em hospitais, a presença de familiares no momento da morte do paciente costuma ser evitada, segundo Menezes (2004) esse ocultamento da morte objetiva proteger a rotina institucional e não o doente ou os familiares, Kovács (2007) compreende que a "proposta de assepsia" (p.218) dos hospitais abrange inclusive aspectos emocionais, de maneira que, para não haver "contágio de sofrimento", reduzem ou impedem a expressão de sentimentos e a proximidade dos familiares no momento da morte.

Alguns pacientes sertanejos mostram uma visão diferente dessa situação. Estar no momento da morte não é evitado, é reconhecido como êxito, dádiva, companheirismo e dedicação ao outro. No relato de Dona Conceição, também chama a atenção a descrição do momento da morte de seu pai: "Ele morreu eu tava lá, lembro demais, tinha minhas irmãs, gente que tinha ido visitar ele, um bocado de gente, três menino sobrinho meu e outros das mulher vizinha." A morte vivenciada de maneira familiar, com a presença de amigos, parentes e, inclusive, crianças, contrasta com a morte que acontece nas instituições, onde o poder de decisões está nas mãos dos profissionais e gestores (Menezes, 2004).

A participação na cena da morte é aceita e importante. Porém, não se trata de um momento romântico ou de pouca emoção, é relatado como gerador de sofrimento e pesar, mas que pode ajudar no trabalho de luto, como evidencia a fala da entrevistada Maria: "ainda hoje tenho essa conformação, de ter a lembrança do último suspiro da minha mãe".

Formas de enfrentamento. Uma pequena parte da fala da entrevistada Conceição, 58 anos, ilustra bem a fé como principal forma de enfrentamento utilizada pelos sertanejos. Ela relatou: "Quando eu sei de mortes, eu fico assim... seja o que Deus quiser, eu me conformo". A Deus é atribuído a escolha do momento da morte, há uma compreensão de que existe "uma hora" e que cada um tem a sua já determinada. A concepção de que algo maior e mais poderoso que os homens organizam os acontecimentos na vida das pessoas, incluindo as mortes, atribui sentido à perda (Macieira, 2009; Gorzoni, 2005). O conforto é dado pela sensação de que a morte não foi fruto da responsabilidade de alguém, de um sistema ou da sociedade, mas de um caminho já traçado e que só poderá ser compreendido por Deus. Como mostra o excerto de entrevista de Dona M. Josefa, que relata seu processo de luto pela quarta filha que perdera:

Tudo é por Deus minha filha, tudo que Deus faz é bem feito... Aí eu me conformei que já tinha se passado três pra trás. A minha mãe dava conselho, o marido... que era assim mesmo, que Deus queria ela, porque se era de mais pra frente ter uma sorte ruim, então era Deus. (M. Josefa, entrevista pessoal, 14 de abril de 2009).

Segundo Maciera (2009), na maioria das vezes a espiritualidade está ligada a um enfrentamento positivo do adoecer, com baixo escore de depressão, porém se o paciente entende a doença como punição, sente-se culpado ou crê que a prece e a fé podem curar e essa cura não acontece, pode haver piora na qualidade de vida. Os pacientes entrevistados possuíam a visão de um Deus benevolente que, apesar dos sofrimentos, reservava para eles um futuro venturoso, essa postura está ligada à resignação com que os entrevistados relatam as perdas sofridas.

O depoimento de Dona M. Severina, citado abaixo, exemplifica a relação dos entrevistados com o medo da morte, bastante diversa da que encontramos em muitas pessoas de centros urbanos, que expressam medo do envelhecimento, adoecimento e qualquer outra temática ligada ao morrer, em uma incessante busca do ideário da juventude eterna e imortalidade (Boia, 2006; Di Nola, 2007).

Que conversa de morrer, eu não tenho medo de morrer. De qualquer jeito eu num vou? Tenho medo não minha filha, tenho de jeito nenhum, sempre eu num vou? Deus num vai me levar? Com medo ou sem medo? É melhor ir sem medo. (M. Severina, entrevista pessoal, 5 de maio de 2009).

As formas de enfrentamento utilizadas pelos entrevistados são ligadas à fé, à resignação e aceitação; nem por isso são fáceis e isentas de sequelas, como Seu Severino atestou em sua fala: "Quando tenho uma tristeza eu rebolo os sentidos pra longe e deixo pra lá. Dou um chute nos sentidos, mas machuca, pra mudar os sentido machuca nem que seja o dedinho. Tem que ter insistência”. (Severino, entrevista pessoal, 13 de março de 2009).

Rituais funerários. De acordo com Howarth e Leaman(2004), há várias explicações para a existência e importância de rituais fúnebres, desde o medo do regresso dos mortos à necessidade de consolar os vivos. Esses rituais variam muito de uma sociedade a outra e permitem a adaptação do ser humano à morte, Kovács (2007) esclarece que os rituais são específicos de cada cultura, pois facilitam a expressão de sentimentos e dão um significado à perda. Na tradição cultural sertaneja, o termo sentinela designa todo o período, desde a iminência da morte até o enterro; segundo Rocha (2006), a sentinela acontece em função do "finado", porém, exerce importante papel no processo de luto dos vivos e é motivo para encontros e convivência familiar.

Durante as entrevistas desta pesquisa, alguns colaboradores se referem a rituais funerários tradicionais no sertão. Dona $\mathrm{M}$. Josefa descreveu como é a sentinela: "É daquele jeito, vem o povo visitar, aí passa o dia todin tem que fazer comida e cai muita cachaça, botam vela na mão.” (M. Josefa, entrevista pessoal, 14 de abril de 2009). Seu Severino retratou o ritual fazendo 
referência ao acompanhamento do momento da morte:

Se você chegasse e encontrasse uma pessoa doente ficava por ali acompanhando, sempre ficava uns acompanhando, na sentinela, aí quando via que a pessoa tava ruim mesmo a gente juntava as mão e botava vela, aí ficava segurando até a hora da morte levar ela. (A. Severino, entrevista pessoal, 13 de março de 2009).

Todos esses rituais citados são concebidos, segundo Rocha (2006), como "instrumento de intercessão em favor da alma do morto, tendo como principal finalidade o livramento do inferno" (p.57).

Percebe-se, no entanto, a intervenção de novos valores e práticas. Os rituais são construídos e mantidos culturalmente; sofrem influência dos valores e crenças de uma comunidade, em uma relação de mutualidade com esta. Modificações nas tradições acontecem, pois a cultura é uma rede de significados interconectada por indivíduos e pela coletividade, que não é estática e se recria continuamente (Costa, 2004). Os entrevistados desta pesquisa citaram, em alguns momentos, modificações nas formas tradicionais de lidar com o morrer em suas comunidades:

É aqui é (no hospital), a família recebe só o corpo, lá é em casa, com aqueles vizinhos, moradores, aquelas pessoas conhecidas faziam questão de tarem ali até a hora. Depois ficavam visitando aquela família, ajudando, aconselhando. Hoje a pessoa morre e poucos dias...Esquecido, tá esquecido. (A. Severino, entrevista pessoal, 13 de março de 2009).

Seu Severino é testemunha das mudanças em sua comunidade, aos 79 anos já pôde vivenciar a morte de diversas maneiras e acompanhar as modificações nos rituais praticados. Sua fala anterior mostrou as alterações na rede social de apoio à família, em que as visitas de ajuda e aconselhamento deram lugar ao esquecimento. Quando, nesta dissertação, considera-se que o sertanejo lida com a morte de maneira familiar e com maior aceitação, não se afirma que ela seja banalizada ou negada. Já os processos contemporâneos de temor e negação da morte trazem, também, a negação do morto, o seu esquecimento. Seu Severino nos expôs, por meio de seu relato, o processo de medicalização por qual passa a morte, segundo Menezes e Heilborn (2007) a medicalização modifica as práticas médicas em consequência da evolução tecnológica e a medicalização social liga eventos como parto, envelhecimento e morte à técnica médica.

Quando eu cai doente. Outro tema emergente foi intitulado, "Quando eu caí doente", e faz uma referência à doença enquanto Illness, ou seja, experiência do adoecimento como vivida pelo sertanejo quando este se reconhece sem saúde. Seu Severino descreveu sua vivência do adoecimento e realçou a importância da construção de uma boa relação entre pacientes e profissionais. Expôs sua compreensão da palavra paciente, a partir de sua vivência na condição de um: "Bem, o paciente chamam ele paciente, mas é impaciente cheio de dor, cheio de mal estar, cheio de tudo enquanto." (A. Severino, entrevista pessoal, 13 de março de 2009).

Os depoimentos dos colaboradores trazem referências a diagnósticos pouco claros, e a doença, muitas vezes, não é nomeada, aumentando a ansiedade e o estigma. As dificuldades de acesso à saúde promovem diagnósticos tardios e consequentes repercussões no desenvolvimento da doença.

Durante as entrevistas, emergiram algumas compreensões a respeito do câncer, a mais recorrente característica citada foi a da possibilidade do retorno da patologia. Na descrição que Seu Severino faz da doença, ele realizou um jogo com a palavra canso/ "canço", entrelaçando seus significados de cansaço e de câncer (canço, no seu linguajar). O paralelo estabelece a propriedade, em sua opinião, que tem o câncer de cansar o seu portador: "ela vem matar o cara depois de uns anos", como explica Severino a seguir:

Eu acho assim: canço chamam uma doença que vai matando devagar, porque ela é cansativa, vai cansando o cara, vai cansando aí é o canço, vai matando no cansaço. Não chamo mais canço não, é cansaço. É que ela vem matar o cara depois de uns anos, mas ele não sabia que tava com ela, quando vai descobrir ela já vinha no cara há muitos anos. (A. Severino, entrevista pessoal, 13 de março de 2009).

Os colaboradores relatam fazer uso da medicina alopática, mas também recorrem a conhecimentos populares e orações, realidade também apontada em Gorzoni (2005). O profissional de saúde, conhecendo essa realidade, deve propor estratégias terapêuticas que contemplem a diferença e não estabelecer uma disputa entre diferentes visões de saúde e doença.

As concepções sobre o processo de adoecimento, suas causas e tratamentos são moduladas por aspectos socioculturais (Helman, 2006). Durante as entrevistas, a compreensão de que os aspectos emocionais e sociais podem gerar doenças foi recorrente, e demonstra uma visão mais holística do ser humano, baseada não só no individualismo, mas também em suas relações sociais. Os processos de adoecimento e morte foram explicados tanto pela vontade de Deus como por crenças em proibições de certos alimentos ou comportamentos. Desse modo, o ser humano busca formas de compreender os infortúnios, e essas explicações dão um sentido à perda e uma sensação de maior segurança.

O nome dado ao terceiro tema emergente foi "O mundo está em toda parte, o mundo está dentro da gente”, e parafraseia Guimarães Rosa, representando a situação do ser humano como constituído em mutualidade com seu mundo, recebendo influências de outras culturas, de modo a integrar novos elementos na construção de uma realidade cultural própria. A realidade de alternância entre fartura e pobreza se apresenta na vida do sertanejo, e a convivência com essas polaridades coloca essas pessoas em uma situação de transitoriedade, em que os sucessivos ciclos de ganhos e perdas impedem uma sensação de perenidade e segurança.

\section{A experiência no campo}

O vivido da pesquisadora na casa de apoio do hospital. Durante a imersão no campo, um tema já discutido nas entrevistas fenomenológicas emergiu novamente, com maior clareza; tratase de uma discussão promovida na antropologia médica, em Kleinman (1980), sobre os termos disease, illness e sickness. A manifestação fisiológica da doença pode não coincidir com a percepção subjetiva que o indivíduo tem dela, e a expressão social, da mesma patologia pode, ainda, ser diversa das duas anteriores. Disease é a doença na compreensão biomédica; illness é um termo ligado à percepção, pelo indivíduo, de seu estado de 
saúde; e sickness, a dimensão social do adoecer.

Durante as visitas à casa de apoio do hospital, um paciente relatou sua dificuldade em comer e narrou todo o seu adoecimento e tratamento. Ele enfatizou que há muitos anos vem fazendo tratamento para câncer, mas só agora ficou doente, porque antes fazia tudo e agora está com dor e sem conseguir comer. Assim, ficam claras as diferentes visões do processo de adoecimento, pois a realização de um tratamento antineoplásico pressupõe um diagnóstico de câncer, que, no paradigma dos profissionais de saúde, significa estar doente (disease). Porém, o paciente afirma só ter ficado doente agora, anos depois de já fazer o tratamento, pela razão de que só atualmente teve suas atividades prejudicadas e se percebeu com uma doença (illness). Essa diferença entre os momentos do "adoecimento biomédico" e o "sentir-se doente" pode ser entendida segundo a dimensão social da enfermidade para o paciente (sickness). A ideologia dominante, infiltrada em muitos indivíduos das classes trabalhadoras é que a doença só é vista como tal quando é capaz de prejudicar ou impedir a capacidade produtiva do indivíduo, de modo que sintomas ou diagnósticos sem essa característica não são elaborados como estar doente.

O vivido da pesquisadora nas cidades do sertão nordestino. Durante a observação participante, realizada nas cidades de origem de dois colaboradores, percebeu-se que, assim como nas entrevistas fenomenológicas, muitos costumes tradicionais ainda são mantidos, e a relação do sertanejo com a morte, em comparação às pessoas de grandes centros urbanos, é mais próxima e familiar. Porém, algumas mudanças já verificadas nas entrevistas fenomenológicas surgiram com maior intensidade durante as visitas às cidades. Atualmente, o discutível processo de globalização diminui o isolamento das mais remotas áreas povoadas, levando às comunidades novas tecnologias em saúde, educação e política. Mas, oferece também o risco da massificação de valores, da gradativa aculturação e da perda de tradições e costumes que lhes conferiam uma identidade cultural própria, pois passam a associar a tradição ao atraso e o novo ao progresso (Costa, 2004; Matos, 2006).

O alastramento de uma rede de funerárias no sertão foi observado nas visitas às cidades dos pacientes. Reflexo do movimento "funeral homes", originado nos Estados Unidos, as empresas funerárias presentes nas cidades visitadas disseminam uma nova forma do sertanejo lidar com os rituais funerários. A morte ainda é vista como natural e inevitável, porém, seus rituais passam a ser, também, produtos, vendidos de forma padronizada, inspirado nos modelos de "lugares desenvolvidos" e com um ideal de modernidade. Amorte como produto de consumo encerra novos desejos e necessidades antes desconhecidos pela comunidade e a chegada de práticas e valores externos é vista como sinal de desenvolvimento, como mostra outra vinheta: "trabalham 'no estilo capital'(...) na frente da loja não tem caixão, ficam guardados". O que era visto como natural e conhecido deve, agora, ser escondido.

O antropólogo italiano Alfonso di Nola (2007), observou que as profundas transformações sociais tem tido como consequência o desaparecimento de muitos costumes antigos, que ainda sobreviviam em zonas rurais, mas que algumas observações já sugerem sua extinção. Di Nola afirmou que cada sociedade elabora seu sistema de crenças, destinado a explicar a morte, e um conjunto de rituais que pretendem dar uma resposta social às emoções suscitadas pelo luto e considera um fator negativo que se estejam deixando de lado os ritos.

As promessas vendidas pelo mercado funerário reacendem desejo humano de juventude eterna, aspiração antiga, mas que encontra terreno fértil no contexto material e mental de nossa época, expressou Lucian Boia (2006), historiador francês que entende que as soluções que a técnica cientifica já é capaz de oferecer colocam o homem em uma incessante busca da juventude eterna e da imortalidade. Mostra desse processo é a afirmação de uma paciente entrevistada expressando contentamento com o tratamento estético dado aos corpos na funerária onde ela pagava seu seguro funerário: "Fica bem novinha, um vein fica novin assim como a senhora. Eles botam maquiagem minha filha, uma coisa linda, ficam bem novin".

\section{Considerações finais}

Para o sertanejo com câncer, o tema morte é menos interdito, em relação às sociedades urbanas contemporâneas, ele a percebe como um dever, doloroso, mas inevitável e esperado. Sua compreensão de adoecimento e morte envolve aspectos psicossociais e o caráter universal do morrer é confirmado por meio de suas sucessivas vivências de perda. Percebeu-se que a dor pela perda é reconhecida como intensa, mas a reabilitação é vista como necessária.

Os sertanejos entrevistados consideram a presença no momento da morte de algum familiar como uma demonstração de dedicação ao outro, além de ser uma experiência reconfortante no período do luto. A morte é compreendida por eles, como destino determinado por Deus, fato que contribui para seu enfrentamento com resignação, o que dá sentido à perda, facilitando o processo de luto. Em relação às formas de enfrentamento, uma das mais utilizadas é a fé. Durante o tratamento os pacientes relataram fazer uso conjunto da medicina, dos conhecimentos populares e das orações.

A dinâmica do tratamento dos pacientes foi um fator limitante nesta pesquisa, altas inesperadas ou adiadas faziam com que o entrevistado permanecesse mais tempo internado ou retornasse mais cedo para sua cidade, não estando presente na casa de apoio na data da segunda entrevista, assim alguns participantes não puderam ser incluídos na pesquisa, além do óbito de um dos entrevistados entre a primeira e a segunda entrevista.

Um ponto importante observado merece futuras pesquisas: os rituais funerários tradicionais no sertão. Eles estão sendo modificados por novos valores "globalizados", que incorporam os ideais de modernidade já em voga nos grandes centros urbanos.

Apesar dessas mudanças contemporâneas, o cerne da questão da morte para o sertanejo permanece: sua visão de vida, que insere, continuamente, a morte nas possibilidades do ser.

\section{Referências}

Ariès, P. (1990). O homem diante da morte. Rio de Janeiro: Francisco Alves. Ariès, P. (2003). História da morte no ocidente. Rio de Janeiro: Ediouro. 
Boia, Lucian (2006). Quand les centenaires seront jeunes. Paris: Les Belles Lettres.

Bowlby, J. (1973). Perda: tristeza e depressão. São Paulo: Martins Fontes.

Costa, T.C. (2004). A mundialização da cultura e os processos de homogeneização e formação da cultura global. Universitas - Relações Internacionais, 2(1), 255-267.

Cunha, E. (2007). Os Sertões: campanha de canudos. São Paulo: Martin Claret.

Denzin, N.K., \& Lincoln Y.S.(2007). O planejamento da pesquisa qualitativa, teorias e abordagens. Porto Alegre: ArtMed.

Di Nola, A. M. (2007). La muerte derrotada: antropologia de La muerte y el duelo. Barcelona: Belacqva.

Ewald, A., \& Soares, J. C. (2007). Identidade e subjetividade numa era da incerteza. Estudos de Psicologia, 12(1), 23-30.

Freire, P. (2005). Pedagogia do oprimido. (46 ${ }^{\mathrm{a}}$ Ed.) Rio de Janeiro: Paz e Terra.

Gorzoni, P. (2005). Mulheres de fé. Revista Raizes. Dez. 69-76.

Helman, C.G. (2006). Cultura, Saúde \& Doença. Porto Alegre: Artmed.

Howarth, G., \& Leaman (2004). Enciclopédia da morte e da arte de morrer. Lisboa: Quimera.

Kleinman, A. (1980). Patients and healers in the context of culture. Berkeley: University of California Press.

Kleinman, A. \& Good, B. (1985). Culture and depression: studies in anthropology and cross-cultural psychiatry of affect and disorder. Berkeley: University of California Press.

Kovács, M. J. (2002). Morte e desenvolvimento humano. São Paulo: Casa do Psicólogo.

Kovács, M. J. (2007). Perdas e o processo de luto. In D. Incontri \& F. S. Santos (Orgs.), A arte de morrer: visões plurais (pp.217-238). Bragança Paulista: Editora Comenius.

Kubler-Ross, E. (2005). Sobre a morte e o morrer. São Paulo: Martins Fontes.

Langdon, E. J. (2001). A doença como experiência: o papel da narrativa na construção sociocultural da doença. Etnográfica, 2, 241-260.

Macieira, R.(2009). Enfrentamento do câncer e espiritualidade. In F. S. Santos (org.), A arte de morrer: visões plurais Vol. 2. pp.237-245. Bragança Paulista: Comenius.

Matos, Olgária (2006). Discretas esperanças. São Paulo: Nova Alexandria.
Melo Neto, J.C. (2000). Morte e Vida Severina e outros poemas para vozes. ( $4^{\mathrm{a}} \mathrm{Ed}$.) $\mathrm{Rio}$ de Janeiro: Nova Fronteira.

Menezes, R. A.(2004). Em busca da boa morte: antropologia dos cuidados paliativos. Rio de Janeiro: Garamond.

Menezes, R.A., \& Heilborn, M. L. (2007). A inflexão de gênero na construção de uma nova especialidade médica. Estudos Feministas, Florianópolis, 15(3), 563-580

Merleau-Ponty, M. (1975). O olho e o espirito. Coleção Os Pensadores. São Paulo: Abril Cultural.

Merleau-Ponty, M. (2006). Fenomenologia da percepção. São Paulo: Martins Fontes.

Moreira, V.(2004). O Método fenomenológico de Merleau-Ponty como ferramenta crítica na pesquisa em psicopatologia. Psicologia: Reflexão e Crítica, 17(3), 447-456.

Moreira, V., \& Cavalcante Jr, F.S. (2008). O método fenomenológico crítico (ou mundano) na pesquisa em psico(pato)logia e a contribuição da etnografia. Estudos e Pesquisas em Psicologia, 8(2), 245-260.

Morin, E. (1970). O homem e a morte. Lisboa: Publicações Europa-América.

Rocha, E (2006). Benditos fúnebres nas sentinelas do Cariri(CE). Revista Anthropológicas, ano 10, 17(1), 49-66.

Rodrigues J, C. (2007). A morte numa perspectiva antropológica. In D. Incontri, \& F. S. Santos(Orgs.), A arte de Morrer: Visões Plurais (pp. 129-136). Bragança Paulista: Editora Comenius.

Rosa, J. G. (2007). Grande sertão: veredas. Rio de Janeiro: Nova Fronteira.

Silva, M. L.G., \& Salvajoli, J. V. (2008). Radioterapia. In V. A. Carvalho (Org.), Temas em Psico-Oncologia. São Paulo: Summus.

Soares, J. C., \& Dantas, M. A.(2006). Considerações sobre a morte e o morrer na hipermodernidade. Estudos e Pesquisas em Psicologia, 6( 2), 89-104.

Straub, R. O.(2002). Psicologia da saúde. Porto Alegre: Artmed.

Valle, E. R. M., Borges, A. D. V. S., Silva, E. F., Toniollo, P. B., Mazer, S. M., \& Santos, M. A.(2006). Percepção da morte pelo paciente oncológico ao longo do desenvolvimento. Psicologia em Estudo, Maringá, 11(2), 361-369.

Villa, M. A. (2000). Vida e morte no sertão: história das secas no nordeste nos séculos XIX e XX. São Paulo: Ática.

Worden, J. W. (1998). Terapia do luto. Porto Alegre: Artes Médicas.

Agradecimentos

Apoio financeiro da FUNCAP.

Lana Veras, mestre em Psicologia pela Universidade de Fortaleza, doutoranda, bolsista CAPES em Psicologia Social pela Universidade do Estado do Rio de Janeiro. Endereço para correspondência: Rua Le Corbusier, 50, apartamento 701, bloco 2, Recreio, Rio de Janeiro-RJ. CEP 22.785-295. Telefones: (21) 8267-3070 e (21) 3546-5821.E-mail: lanaveras@hotmail.com

Virginia Moreira, pós-doutora em Antropologia Médica pela Harvard University, doutora em Psicologia Clínica pela Pontifícia Universidade Católica de São Paulo, é professora titular do Programa de Pós-Graduação da Universidade de Fortaleza. E-mail: virginiamoreira@unifor.br 